\title{
COMPARISON OF TERRESTRIAL GAMMA DOSE RATE MAPS IN BORDER AREAS - A STUDY FOR MAP REGIONAL UNIFICATION
}

\author{
Milan Matolín \\ Faculty of Science, Charles University, \\ Albertov 6, 12843 Prague 2, Czech Republic
}

\section{RADIOMETRIC MAPS AND THEIR APPLICATION}

Terrestrial radiation, the substantial component of the natural radiation environment, is variable with the geological setting of the earth surface. Potassium, uranium decay series, and thorium decay series are fundamental sources of radioactivity of rocks. Radiometric maps, describing the gamma dose rate or concentration of natural radioactive elements, are used in environmental studies, estimation of absorbed radiation dose from terrestrial radiation, geological investigations, exploration of raw materials, delimitation of regions of radon risk and they provide a base against which man made contamination can be estimated. A series of radiometric maps has been published (IAEA 1995).

\section{CAUSES OF RADIOMETRIC DATA DEVIATIONS}

Maps of terrestrial gamma dose rate, usually expressed in $n G y \cdot h^{-1}$, specify the natural radiation environment. Technique of measurement, data processing and compilation of radiometric maps contribute to resultant data deviations. Substantial influence on results may have technical parameters of used instruments, calibration facilities and method of instruments calibration, geometry, density and the mode of field radiometric measurement, data processing, data levelling and their graphical presentation. If maps are used for the assessment of the natural radiation environment, reliability of reported gamma dose rate values must be acceptable and should be checked.

\section{RADIOMETRIC MAP OF THE CZECH REPUBLIC AND ITS VERIFICATION}

Radiometric map of the Czech Republic 1:500000, published in 1995 (Manová, Matolín 1995), expressed in gamma dose rate, is based on regional (1957-1959) and detailed (1960-1971) airborne total count measurement, airborne gamma ray spectrometry (from 1976 onward), and is completed by ground radiometric survey. Original airborne maps of contours, on the scale 1:200000, has been converted to vector form by digitizing and expressed by 871652 data in a regular grid $300 \times 300 \mathrm{~m}$ over the territory. Back calibration was applied in 1994 to convert the data to dose rate and to level the map. Map of.contours, with the step of $10 \mathrm{nGy} \cdot \mathrm{h}^{-1}$, was compiled by computer processing using the method of kriging. Regional terrestrial radiation in the Czech Republic, formed by magmatic, 
sedimentary and metamorphic rocks, is in the range 15-200 (6-245) nGy.h $\mathrm{h}^{-1}$, with the mean $65.6+/-19.0 \mathrm{nGy} \cdot \mathrm{h}^{-1}$.

A series of factors affect resultant radiometric data. Verification of the Radiometric map of the Czech Republic 1:500000 was carried out in 1995 and 1996 by comparison with ground gamma ray spectrometry measurements.

In 1995, 81 regional traverses 1-5 km long, situated on rocks of high, medium and low radioactivity, in the whole area of the Czech Republic, has been measured with calibrated portable gamma ray spectrometer GS-256, totally at 761 segments of the length of $200 \mathrm{~m}$, with exposure time 2 min. per segment, in dynamic mode. Results of ground measurement were expressed in dose rate, averaged in each traverse, and compared with gamma dose rate values of the radiometric map 1:500000. The average difference of compared data sets $2.1 \mathrm{nGy} \cdot \mathrm{h}^{-1}$ shows good regional dose rate data levelling, while the mean deviation $+/-13.8 \mathrm{nGy} . \mathrm{h}^{-1}$ illustrates expected differences at individual sites. Coefficient of correlation of compared data sets $(\mathrm{N}=81)$ is 0.942 .

In 1996, ground gamma ray spectrometry measurement of the area $6 \times 6 \mathrm{~km}$ at 49 stations in regular grid $1 \times 1 \mathrm{~km}$, in static mode, with exposure time $4 \mathrm{~min}$,, was carried out at Lovosice, northern Bohemia, in an area formed by Cretaceous sediments. Mean of determined gamma dose rate was $50.7 \mathrm{nGy} \cdot \mathrm{h}^{-1}$ and median $53 \mathrm{nGy} \cdot \mathrm{h}^{-1}$, what is comparable with the interval 50-60 nGy. $\mathrm{h}^{-1}$ indicated by the radiometric map 1:500000.

In 1996, 50 traverses, each $1 \mathrm{~km}$ long, situated in the area of the Czech Republic along the Czech-German (Saxony) border, in the geographical traverse Vojtanov-Hrádek nad Nisou of the length $200 \mathrm{~km}$, has been measured with portable gamma ray spectrometer GS-256, in dynamic mode, over 255 segments of the length of $200 \mathrm{~m}$, with exposure time $2 \mathrm{~min}$. per segment. Results were averaged for each traverse and compared with the radiometric map 1:500000. Average difference of compared data sets is $1.7 \mathrm{nGy} \cdot \mathrm{h}^{-1}$ with the mean deviation $+/-12.9$ nGy.h ${ }^{-1}$

\section{COMPARISON OF TERRESTRIAL GAMMA DOSE RATE DATA IN BORDER} AREAS

Radiometric maps of Saxony 1:400000 and the Czech Republic 1:500000 has been compared in border areas in 1996. Radiometric map of Saxony is based on ground radiometric measurements at 1026 stations in a regional grid cca $4 \times 4 \mathrm{~km}$ (Borsdorf, Malinowski 1994). Radiometric data were compared along the border sector of the length of $250 \mathrm{~km}$ at 66 contiguous sites. Mean difference $9.9 \mathrm{nGy} \cdot \mathrm{h}^{-1}+/-13.6 \mathrm{nGy} \cdot \mathrm{h}^{-1}$, with higher values in Saxony, is interpreted as the effect of surface nuclear fall out contamination that has been detected with natural rock radiation. General radiometric features of the Ore Mountains (Erzgebirge) area, with high radioactivity of Nejdek-Eibenstock granite massif, Teplice ryolite etc. were confirmed on both sides of the border.

Radiometric maps of Poland 1:750000 and the Czech Republic 1:500000 has been compared in border area in 1997. Radiometric map of Poland is based on ground gamma ray spectrometry measurements at 19528 stations on N-S regional traverses separated $17 \mathrm{~km}$ with distance of stations $1 \mathrm{~km}(0.5 \mathrm{~km})$. Measurement was carried out with portable gamma ray spectrometer GS-256 calibrated in the Czech Republic (Strzelecki et al. 1993). Data of terrestrial gamma dose rate were compared along the Czech-Polish border sector of the length 
of $300 \mathrm{~km}$ at 49 contiguous sites. Mean difference $12.1 \mathrm{nGy} \cdot \mathrm{h}^{-1}+/-13.6 \mathrm{nGy} \cdot \mathrm{h}^{-1}$, with higher values in the Czech Republic, indicates the inconsistency of local radiometric data derived by interpolation from various grids of measurement on both sides of the border.

\section{ANALYSES OF RADIOMETRIC DATA COMPARISON}

Differences in radiometric data comparisons were observed. Since the test measurement with various radiometric instruments at common sites in various geological setting showed a good fit, the differences in maps are mainly due to the data grids, data processing and necessary interpolation. Different detection range of airborne measurement, averaging the data, and ground local measurements, instrument calibration inconsistency and instrument gamma energy response contribute to deviations. Unification of gamma radiometric maps on continental scale requires source data analysis, their back calibration and additional check tie lines. Radiometric maps maintain well general radioactivity features, while local data reliability can be affected by various phenomena.

\section{ACKNOWLEDGMENTS}

Funding for the research was provided by the grant of Charles University No. 131. Thanks are expressed to the authors of radiometric map of Poland and radiometric map of Saxony enabling comparison.

\section{REFERENCES}

Borsdorf K.H., Malinowski D. (1994): Karte der Gammaenergie-dosisleistung 1:400000. BGR, Berlin

INTERNATIONAL ATOMIC ENERGY AGENCY (1995): Application of uranium exploration data and techniques in environmental studies. IAEA-TECDOC-827, IAEA, Vienna

Manová M., Matolín M. (1995): Radiometric map of the Czech Republic 1:500000. Czech Geol. Survey, Prague, 1-19

Strzelecki R., Wolkowicz S., Szewczyk J., Lewandowski P. (1993): Radioecological maps of Poland (Part II, Maps of U, Th, K concentration in Poland). Polish Geological Institute, Warsaw 
